\title{
Coronary Artery Circumferential Stress: Departure from Laplace Expectations with Aging
}

\author{
Richard E. Tracy ${ }^{1, *}$ and Marsha L. Eigenbrodt ${ }^{2}$ \\ ${ }^{1}$ Department of Pathology, Louisiana State University Health Sciences Center, New \\ Orleans; ${ }^{2}$ Adjunct Department of Internal Medicine, University of Arkansas for \\ Medical Sciences, Little Rock \\ E-mail: rtracy@Isuhsc.edu; meigenbrodt@sbcglobal.net
}

Received March 2, 2009; Revised August 18, 2009; Accepted August 31, 2009; Published September 15, 2009

\begin{abstract}
Normal, youthful arteries generally maintain constant radius/wall thickness ratios, with the relationship being described by the Laplace Law. Whether this relationship is maintained during aging is unclear. This study first examines the Laplace relationships in postmortem coronary arteries using a novel method to correct measurements for postmortem artifacts, uses data from the literature to provide preliminary validation, and then describes histology associated with low circumferential stress. Measurements of radius and wall thickness, taken at sites free from atheromas, were used with national population estimates of age-, gender-, and race-specific blood pressure data to calculate average circumferential stress within demographic groups. The estimated circumferential stress at ages 55-74 years was about half that at ages 18-24 years because of a disproportionate increase of wall thickness relative to artery radius at older ages, violating the expected relationships described by the Laplace Law. Arteries with low circumferential stress (estimated at sites distant from atherosclerosis) had more necrotic atheromas than arteries with high stress. At sites with low stress and intimal thickening, smooth muscle cells (SMCs) were spread apart, thereby diminishing their density within both the intima and media. Thus, older arteries displayed both low circumferential stress and abundant matrix of low cellularity microscopically. Such changes might alter SMC-matrix interactions.
\end{abstract}

KEYWORDS: aging, arteriosclerosis, atherosclerosis, human, intima-media thickness

\section{INTRODUCTION}

Separating arterial features of ordinary aging from those of atherosclerosis using various kinds of in vivo imaging techniques has been difficult in the past[1,2]. Postmortem histological specimens, when examined with attention to their limitations, can minimize some of these problems. Under physiologic conditions, the Laplace Law has been widely used by numerous investigators to explain the constancy of arterial wall thickness to lumen radius needed to maintain constant circumferential stress in the wall of the pressurized cylinder in a wide range of circumstances. Wolinskey and Glagov[3], for instance, measured wall-to-lumen ratios of abdominal aortas from a variety of mammalian species. From their data, assuming 
pressures of $100 \mathrm{mmHg}$, it is possible to calculate circumferential stress of 240,000 and 284,000 newtons per square meter $\left(24.0\right.$ and $\left.28.4 \times 10^{4} \mathrm{~N} / \mathrm{m}^{2}\right)$ for the averages of three mice and four bulls, respectively, a magnitude not significantly variable over a 20 -fold range of aortic sizes. Other species (rat, cat, rabbit, dog, human, sheep, pig, and horse) all fell close to this same narrow range of values. In human arteries, however, data from postmortem specimens have repeatedly raised doubts about the constancy of radiusto-thickness ratios as a general property of aging atheroma-free arterial sites[4,5].

Much evidence suggests that the radius increases with age in human arteries, a process often ascribed to fractures of load-bearing elastin fibers in response to the fatiguing effect of tensile stress[6]. Wall thickness also increases with age[7,8], and the Laplace Law has sometimes been invoked to imply that the artery radius-to-wall thickness ratio should be held constant if the aging changes are the result of physiological adaptation[8]. This study was designed to examine the relationship of wall thickness, radius, estimated circumferential stress, and histologic features in right coronary arteries retrieved in a series of medico-legal autopsies.

So that atherosclerotic lesion thickening and remodeling would not cause biased calculations of circumferential stress, measurements were made at sites lacking any evidence of atherosclerosis.

\section{METHODS}

\section{Source of Material}

Coronary arteries were retrieved at autopsy from men and women of black and white ethnic groups aged $18-74$ years in the Orleans Parish Coroner's Office in 2004-5 $(\mathrm{n}=207)$. Only subjects with the rightdominant or balanced patterns of coronary circulation were retained. Left-dominant patterns, which affect about $10 \%$ of hearts, were excluded. A basal autopsy category was constructed using the subset of 182 subjects with deaths from violence, or from natural causes having no known relationship with hypertension or atherosclerosis. This basal group approximates a representative sample of the population[9] and these subjects were used for the analyses unless otherwise specified. The Institutional Review Board has declared this autopsy design as exempt from their review.

\section{Processing of Specimens}

Each right coronary artery was opened longitudinally from the aortic root to the origin of the posterior descending branch. The heart was suspended by its own weight from a dowel in the tricuspid orifice as a way to distend the valve ring to its fullest extent. A piece of string was laid along the interior surface of the artery on its cardiac side, following the contours of the sometimes tortuous artery. The length of the string was used to estimate the in vivo artery length. Arteries were allowed to shrink by elastic recoil as they were dissected from the heart, then cut into segments, and each segment was flattened by compression with a sponge during formalin fixation. This process usually abolished tortuosity. Each artery's fixed length was the sum of its fixed segments' lengths. In exceptionally rigid tortuous arteries, the fixed segments retained a small arch leftward or rightward after flattening. Since the measured excised length was a straight line across the curves, the excised length in these few especially stiff specimens may have been underestimated slightly. This discrepancy is treated as a small component of residual error.

\section{Retraction Measure (Stiffness Index)}

The length of each fixed artery can be expressed as a proportion of the string length, $f=$ retracted length/h, where $\mathrm{h}$ is the in situ (string) length. This ratio, $\mathrm{f}$, can be used as a stiffness index because it measures the relative failure of the excised specimen to retract. Part of this retraction is a small size 
change occurring during fixation (1-3\%[10]), which is expected to vary little between specimens. The inverse ratio, 1/f, can be used to correct for retraction and shrinkage to estimate the in vivo artery measures. Heart weights were abstracted directly from autopsy protocols.

\section{Circumference Measurement}

After arteries were flattened by pinning onto a cork board, measurements of luminal circumference were made at seven equidistant sites ( $>1-\mathrm{cm}$ separations to assure independence). Luminal circumference was measured at the seven sites using a digital caliper accurate to $0.01 \mathrm{~mm}$, and the mean radius was calculated for the specimen. If an assigned site on the artery was excessively thickened and stiffened by plaques, then a nearby site was substituted. In a few specimens, no substitute site could be found at one or more of the seven sites, and these few specimens were discarded. The coefficient of variability of these measurements averaged $11.5 \%$ in the arteries later found histologically to contain necrotic atheromas, and $13.7 \%(p=0.03)$ in those without atheromas, indicating that, overall, a few widely scattered plaques or poststenotic dilatations did not produce greater unevenness of measured circumference.

\section{Slide Preparation}

Longitudinally oriented samples of the formalin-fixed segments were embedded in paraffin on edge to allow lengthwise sectioning perpendicular to the luminal surface. Sections of 6- $\mu \mathrm{m}$ thickness were stained with hematoxylin and eosin $(\mathrm{H} \& \mathrm{E})$. Shrinkage from the formalin-fixed state during section preparation averaged $17.2 \%$ (SEM $=0.96$ ) in a sample of 20 specimens representing the full range of observed circumferential stresses, which is close to published values[10,11], and this factor was used to adjust histological measurements for this artifactual shrinkage. The correlation of this shrinkage with circumferential stress was $r=-0.05(p=0.84)$, with stiffness $r=0.032(p=0.89)$, with age $r=0.022(p=$ $0.92)$, and with presence of atheroma $\mathrm{t}=0.14(p=0.89)$, showing that these properties of the arteries had minimal influence on the amount of shrinkage during paraffin embedding.

\section{Evaluation of Slides}

Thicknesses of intima and media were measured with an eyepiece micrometer at nine equally spaced positions along the coronary sample (approximately 1-cm separations, sufficient to assure independence), taking the intima plus media to define total wall thickness, excluding adventitia. Counts of smooth muscle cell (SMC) nuclei were taken in an area defined by an eyepiece reticle to span a distance of $100 \mu \mathrm{m}$ along the artery, and across the full thicknesses of intima and media. If sites had necrotic atheroma[4] or fatty streak elements[12], then they were excluded and nuclear counts were taken from nearby locations, so it is unlikely that nuclear counts contained significant numbers of immigrant leukocytes from the blood[13]. Whether aging may alter nuclear size, shape, and orientation is a topic for future quantitative evaluation, but subjectively, change in nuclear morphology does not appear to be a major contributor to the conspicuous expansion of distances between nuclei.

\section{Calculation of Circumferential Stress}

Circumferential stress, $\mathrm{s}$, was based on the simplified formula from the Laplace Law, $\mathrm{s}=\mathrm{mr} / \mathrm{t}$, where the symbols $\mathrm{m}$, $\mathrm{r}$, and $\mathrm{t}$ denote mean arterial pressure $(\mathrm{m})$, luminal radius $(\mathrm{r})$, and wall thickness $(\mathrm{t})$, respectively, as they apply to the living artery. The mean arterial pressure determines the SI units of measure for circumferential stress, $133.3 \mathrm{~N} / \mathrm{m}^{2}$ for each $\mathrm{mmHg}$. 


\section{Estimations of In Vivo Arterial Measures for Calculating Circumferential Stress}

The in situ radius was estimated as $\mathrm{r}=$ circ/ $2 \pi \mathrm{f}$, where circ is the observed mean circumference of the retracted specimen and $\mathrm{f}$ is defined above. This formula assumes that the longitudinal retraction is a reasonable estimate of the circumferential retraction, and this assumption will be examined later in the Discussion section. Using lower case letters hereafter for in situ dimensions, in situ wall thickness, t, which is needed to calculate circumferential stress, can be estimated as follows. Artery wall volume is calculated as the difference between the volumes of the two cylinders described by the outer wall and the lumen. So, for the retracted specimen, volume $=$ length $\times \pi$ (radius + thickness) $^{2}-$ length $\times \pi$ (radius) $^{2}$. Treating as negligible the small effects of formalin fixation, this observed volume is then equated to the in situ volume, $\pi(\mathrm{r}+\mathrm{t})^{2} \mathrm{~h}-\pi \mathrm{r}^{2} \mathrm{~h}=$ retracted volume, in a manner similar to wall area calculations[14], from which $t$ is readily extracted. Observations needed to determine stress in the longitudinal direction were not attempted here[15].

\section{Estimating Mean Arterial Pressure}

Since mean arterial pressure (MAP) is not available in this data set and varies with age, we used published values of age-, gender-, and (black vs. white) race-specific diastolic and systolic blood pressures from the NHANES II[16] national survey data to estimate age-, race-, and gender-specific mean arterial pressures, $\mathrm{m}=\mathrm{MAP}=($ Systolic +2 Diastolic $) / 3$. The survey estimate of MAP for each age, gender, and race group was substituted for the unknown value in each individual; these estimated values are thought to be reasonable approximations for calculating group averages of circumferential stress. Circumferential stress calculations were repeated after substituting systolic for mean blood pressure, because it is unknown whether wall architecture is responsive to mean or systolic pressures.

\section{Reproducibility of Measurements}

The coefficient of variation (CV) for triplicate measurements of the in situ (string) lengths was calculated in16 unselected consecutive hearts and ranged from 0 to $6 \%$, with a median of $1.7 \%$. Circumference measured at multiple sites along the lengths of 207 arteries had CV ranging from 2.6 to $23.9 \%$, with a median of $9 \%$, while wall thickness CV ranged from 7.7 to $69.7 \%$, with a median of $21.5 \%$. Errors in the calculated circumferential stress are clearly dominated by within-specimen biological variation, rather than method error.

\section{Statistical Methods}

Analyses all employ widely used methods offered in the SAS package of computer programs (SAS Institute, Cary, NC). Two-way analysis of variance (ANOVA) between genders and across five levels of age, applied to basal cases, was carried out with PROC GLM so that continuous covariates could be introduced. Heart weight was evaluated as a potential confounder in the derivation of estimated circumferential stress in this way. To derive a cutoff point for discriminating the existence of atheromas within coronary arteries, logistic regression evaluated 124 subjects, ages 35-74 years, with all causes of death; age-specific odds ratios were calculated from the 2 by 2 contingency tables using this cutoff point in all age groups. 


\section{RESULTS}

The findings in all tables derive from 136 men and 46 women who were 18-74 years of age, who had basal causes of death, and included blacks and whites. There were more men than women at all ages, with the greatest discrepancy in numbers being for the ages of 18-34 and 55-74. Occasional inconsistencies between men and women may relate to this deficiency in numbers. The full 207 specimens are used only in a scatter plot.

\section{Artery In Situ Length and Stiffness Index}

After adjusting for insignificant racial differences, both age and gender were significantly associated with tethered artery length overall (Table 1). The tethered length was significantly longer at older ages among men, but age did not reach statistical significance among women where the sample size was smaller, and no significant interaction was found between age and gender $(p=0.42)$. Overall, adjusting for age and race, arteries in men were about $6 \%$ longer than arteries in women. In general, arteries retracted after removal from the heart and fixation even at the oldest ages (Table 1, stiffness index), but retraction was least at the oldest ages so that the excised length represented a large proportion of the in situ length. The loss of retraction in women was about twice the loss found in men over the observed age range, and a statistically significant age-gender interaction was found $(p=0.01)$.

TABLE 1

Age-Specific Means* of Selected Gross Anatomic Characteristics of the Right Coronary Artery in Autopsy Cases with Basal Causes of Death

\begin{tabular}{lccccccc}
\hline \multirow{2}{*}{$\begin{array}{l}\text { Age } \\
\text { (Years) }\end{array}$} & \multicolumn{2}{c}{$\begin{array}{c}\text { Stiffness Index } \\
\text { (Ratio Units) }\end{array}$} & \multicolumn{2}{c}{ Tethered (In Situ) Length (cm) } & \multicolumn{2}{c}{$\begin{array}{c}\text { Number of } \\
\text { Cases }\end{array}$} \\
\cline { 2 - 8 } & Men & Women & Men & Women & All & Men & Women \\
& $0.800 \mathrm{~A}$ & $0.752 \mathrm{~A}$ & $10.6 \mathrm{~A}$ & $10.4 \mathrm{~A}$ & $10.5 \mathrm{~A}$ & 30 & 8 \\
$18-24$ & $0.830 \mathrm{~A}$ & $0.755 \mathrm{~A}$ & $11.2 \mathrm{AB}$ & $9.7 \mathrm{~A}$ & $10.5 \mathrm{AB}$ & 37 & 6 \\
$25-34$ & $0.841 \mathrm{AB}$ & $0.869 \mathrm{~B}$ & $12.1 \mathrm{BC}$ & $11.0 \mathrm{~A}$ & $11.6 \mathrm{BC}$ & 21 & 10 \\
$35-44$ & $0.943 \mathrm{C}$ & $0.882 \mathrm{~B}$ & $11.8 \mathrm{BC}$ & $11.6 \mathrm{~A}$ & $11.7 \mathrm{BC}$ & 21 & 15 \\
$45-50$ & $0.902 \mathrm{BC}$ & $0.955 \mathrm{~B}$ & $12.4 \mathrm{C}$ & $11.9 \mathrm{~A}$ & $12.2 \mathrm{C}$ & 27 & 7 \\
$55-74$ & $0.863 \pm 0.078$ & $0.841 \pm 0.08$ & $11.6 \pm 1.4$ & $10.9 \pm 1.5$ & $11.4 \pm 1.4$ & 136 & 46 \\
Mean $\pm \mathrm{SD}^{\ddagger}$ & & & & & & &
\end{tabular}

Means derive from generalized linear modeling, adjusting for black vs. white racial group as a covariate. Numbers of cases are applicable also to Tables 2-5.

$\dagger \quad$ Excised length/tethered length.

$\ddagger \quad$ Age- and gender-specific means ( \pm standard deviation) are adjusted for race; age-specific means for tethered length are additionally adjusted for gender.

Note: Tests of the main effects of age group on stiffness index $(p<0.001)$ and on tethered length $(p=0.01)$ are significant, while the main effect of gender is significant on tethered length $(p<0.001)$, but not on stiffness $(p=0.13)$; age by gender interactions were significant for stiffness $(p=0.01)$, but not for tethered length $(p=0.42)$. Post hoc tests: a pair of means within a column that fail to share a symbol A, B, C, or D differ significantly at $p<0.05$ by Tukey HSD test. 


\section{Artery In Situ Radius}

The estimated in situ arterial radius (Table 2) also varied significantly with age for men $(p=0.002)$, but not for women $(p=0.90)$, which called for omission of women from segment-specific analysis. The association between age and radius was similar for all three arterial segments among men (age by segment interaction $p=0.75$ ), although paired comparisons did not reach significance by Tukey tests in the distal segment. The significant decrease in arterial radius from the proximal to distal segments was modest as expected. Men tended to have larger radii than women at older, but not at younger, ages; however, the age-gender interaction was not significant $(p=0.26)$.

\section{TABLE 2}

Age-Specific Means* of the Estimated In Situ Radii for Right Coronary Artery, Overall $(n=182)$ and by Gender, and for Longitudinal Segments among Men $(n=136)$ in Cases with Basal Causes of Death ${ }^{\dagger}$

\begin{tabular}{lcccccc}
\hline \multirow{2}{*}{$\begin{array}{l}\text { Age } \\
\text { Years) }\end{array}$} & \multicolumn{3}{c}{ Radius (mm); Men Only } & \multicolumn{3}{c}{ Radius (mm) } \\
\cline { 2 - 4 } & \multicolumn{2}{c}{ Right Coronary Artery Segment } & & & \\
\cline { 2 - 6 } & Proximal & Middle & Distal & Men & Women & All \\
\hline $18-24$ & $1.47 \mathrm{~A}$ & $1.34 \mathrm{~A}$ & $1.23 \mathrm{~A}$ & $1.36 \mathrm{~A}$ & $1.41 \mathrm{~A}$ & $1.39 \mathrm{~A}$ \\
$25-34$ & $1.58 \mathrm{AB}$ & $1.42 \mathrm{AB}$ & $1.27 \mathrm{~A}$ & $1.43 \mathrm{AB}$ & $1.46 \mathrm{~A}$ & $1.45 \mathrm{AB}$ \\
$35-44$ & $1.69 \mathrm{BC}$ & $1.54 \mathrm{ABC}$ & $1.43 \mathrm{~A}$ & $1.55 \mathrm{AB}$ & $1.37 \mathrm{~A}$ & $1.46 \mathrm{AB}$ \\
$45-54$ & $1.63 \mathrm{AB}$ & $1.58 \mathrm{BC}$ & $1.43 \mathrm{~A}$ & $1.54 \mathrm{AB}$ & $1.40 \mathrm{~A}$ & $1.47 \mathrm{AB}$ \\
$55-74$ & $1.75 \mathrm{C}$ & $1.64 \mathrm{C}$ & $1.38 \mathrm{~A}$ & $1.60 \mathrm{~B}$ & $1.44 \mathrm{~A}$ & $1.52 \mathrm{~B}$ \\
Mean $\pm \mathrm{SD}$ & $1.60 \pm 0.26$ & $1.48 \pm 0.26$ & $1.32 \pm 0.26$ & $1.50 \pm 0.24$ & $1.41 \pm 0.25$ & $1.47 \pm 0.24$ \\
\hline
\end{tabular}

* See footnote in Table 1.

$\dagger \quad$ Age- and segment-specific means ( \pm standard deviation) are adjusted for race. Age- and genderspecific means are adjusted for race; age-specific means for men and women combined are adjusted for race and gender.

Note: Main effect of age in men are significant for proximal $(p=0.002)$, middle $(p<0.001)$, and distal ( $p$ $=0.009)$ segments, and the age by segment interactions are not significant $(p=0.75)$. Pooled segment effects of age were significant for men $(p=0.002)$, but not for women $(p=0.90)$; gender effect was significant $(p=0.03)$, but the interaction of age with gender was not significant $(p=$ 0.26). Post hoc tests as in Table 1.

\section{Wall Thickness}

Because the increments for wall thickness, for intimal percentage, and the wall-to-radius ratio were similar in men and women after adjusting for race $(p>0.11$ for interactions with gender), no genderspecific results are shown (Table 3). The thicknesses of the total wall, intima, and media, adjusted for retraction to approximate in situ values, all varied significantly with age $(p<0.001)$. All measures tended to be thicker at older ages after adjusting for race and gender (each $p<0.001$, Table 3 ). The increment for the intima was larger than for the media. The ratio of wall (intima plus media) thickness to radius did not vary significantly by gender $(p=0.11)$, but did vary significantly with age $(p<0.001)$, being larger in the two older groups relative to the three younger ages. In fact, the ratio in the oldest age group was twice that of the youngest age group. The age-adjusted partial correlation of wall thickness with stiffness was $r=$ 0.56 . 
TABLE 3

Age-Specific Means* of Coronary Artery Intimal, Medial, and Total Wall Thicknesses Adjusted for Retraction, \% of the Wall that is Intima, and Thickness/Radius Ratio ( $t / r)$, Derived from 182 Autopsy Cases with Basal Causes of Death

\begin{tabular}{lccccr}
\hline Age (Years) & \multicolumn{3}{c}{ Thickness (mm) } & \multicolumn{1}{c}{$\begin{array}{c}\text { Intima } \\
\text { (\%) }\end{array}$} & $\begin{array}{c}\text { t/r (Ratio } \\
\text { Units) }\end{array}$ \\
\cline { 2 - 4 } & Intima & Media & Total & & \\
\hline $18-24$ & $0.087 \mathrm{~A}$ & $0.123 \mathrm{~A}$ & $0.211 \mathrm{~A}$ & $39.6 \mathrm{~A}$ & $15.3 \mathrm{~A}$ \\
$25-34$ & $0.109 \mathrm{~A}$ & $0.141 \mathrm{~A}$ & $0.250 \mathrm{AB}$ & $43.0 \mathrm{AB}$ & $17.5 \mathrm{~A}$ \\
$35-44$ & $0.144 \mathrm{~B}$ & $0.157 \mathrm{~A}$ & $0.301 \mathrm{~B}$ & $45.6 \mathrm{BC}$ & $21.1 \mathrm{~A}$ \\
$45-54$ & $0.211 \mathrm{C}$ & $0.196 \mathrm{~B}$ & $0.408 \mathrm{~A}$ & $50.5 \mathrm{CD}$ & $28.0 \mathrm{~B}$ \\
$55-74$ & $0.269 \mathrm{C}$ & $0.203 \mathrm{~B}$ & $0.472 \mathrm{C}$ & $54.2 \mathrm{D}$ & $31.4 \mathrm{~B}$ \\
Men, Mean $\pm \mathrm{SD}^{\dagger}$ & $0.175 \pm 0.089$ & $0.180 \pm 0.055$ & $0.355 \pm 0.117$ & $46.0 \pm 11.1$ & $23.8 \pm 8.2$ \\
Women, Mean $\pm \mathrm{SD}^{\dagger}$ & $0.153 \pm 0.092$ & $0.148 \pm 0.056$ & $0.301 \pm 0.121$ & $47.1 \pm 11.5$ & $21.5 \pm 8.5$ \\
\hline
\end{tabular}

* See footnote in Table 1.

$\dagger \quad$ Age-specific means are adjusted for race and gender; gender-specific means ( \pm standard deviation) are adjusted for race and age.

Note: Tests of main effects of age on intima, media, total wall thickness, intima \%, and $t / r$ are all significant $(p<0.001$ in all instances). Main effects by gender are significant for media $(p<0.001)$ and for total wall $(p<0.01)$, but not for intima $(p=0.18)$, for intima \% $(p=0.59)$, or for $\mathrm{t} / \mathrm{r}(p=$ $0.11)$. All interactions of gender by age are insignificant $(p>0.11)$.

\section{Circumferential Stress}

The MAP abstracted from the NHANES II source increased by $17 \%$ for men and $24 \%$ for women from ages 18-24 to 55-74 years (Table 4). Circumferential stress, calculated using these blood pressure values with the estimates of the in situ arterial measures, varied significantly with age $(p<0.001$, Table 4$)$. However, instead of increasing with age as would be expected with the rise in pressure, circumferential stress declined by $41.9 \%$ from the youngest to the oldest ages $(p<0.001$, Table 4$)$. The lower stress at older ages was because the wall thickness increased disproportionately compared to the radius from youth to old age, and therefore overwhelmed the small countervailing effect of MAP in the calculations. Gender was neither a confounder $(p=0.31)$ nor an effect modifier of the age relationship to circumferential stress ( $p=0.27$ for age-gender interactions). Repeating the circumferential stress estimations using systolic pressures showed an absolute decline from 11.3 to $6.8 \mathrm{~N} / \mathrm{m}^{2} \times 10^{4}(39.8 \%)$, indicating no serious disagreement with the proportionate decline obtained using mean pressures. For individual arteries, wall thickness declined in proportion to radius along the arterial length, so that within age ranges, the averages of circumferential stress were always constant along the arterial length of both genders (data not shown).

\section{Relationships to Necrotic Atheroma}

The presence of at least one microscopic necrotic atheroma somewhere in the specimen increased from $1.6 \%$ of the youngest subjects to $75.0 \%$ of the oldest subjects when combining men and women and adjusting for race (Table 4). Circumferential stress measured throughout the nonatheromatous arterial regions tended to be lower in arteries that displayed atheroma elsewhere in the specimen than in those with no atheroma (Fig. 1, vertical line plots the following equation with $\mathrm{W}=0$ as explained next). A logistic regression equation was computed for using stress to determine a cutoff point for separating the specimens with atheroma from those without atheroma: $\mathrm{W}=3.88-0.657 \times$ Stress. 
TABLE 4

Age-Specific Means* of Circumferential Stress and Prevalences of Atheroma in 182 Autopsy Cases with Basal Causes of Death, and Mean Blood Pressure from a Survey Source

\begin{tabular}{|c|c|c|c|c|c|c|c|c|}
\hline \multirow[t]{2}{*}{ Age (Years) } & \multicolumn{3}{|c|}{$\begin{array}{c}\text { Circumferential Stress } \\
\left(10^{4} \mathrm{~N} / \mathrm{m}^{2}\right)\end{array}$} & \multicolumn{3}{|c|}{$\begin{array}{c}\text { Atheroma Prevalence }^{\dagger} \\
(\%)\end{array}$} & \multicolumn{2}{|c|}{$\begin{array}{l}\text { Mean BP } \\
(\mathrm{mmHg})\end{array}$} \\
\hline & Men $^{\S}$ & Women $\$$ & $A l I^{\S}$ & Men $^{\S}$ & Women ${ }^{\S}$ & $A I^{\S}$ & Men & Women \\
\hline $18-24$ & $7.9 \mathrm{BC}$ & $9.4 \mathrm{D}$ & $8.6 \mathrm{C}$ & $4.6 \mathrm{~A}$ & $1.4 \mathrm{~A}$ & $1.6 \mathrm{~A}$ & 91.0 & 84.6 \\
\hline $25-34$ & $7.1 \mathrm{C}$ & $8.4 C D$ & 7.7BC & $17.6 \mathrm{~A}$ & $16.4 \mathrm{~A}$ & $17.0 \mathrm{AB}$ & 95.6 & 87.8 \\
\hline $35-44$ & 7.3AB & $6.6 \mathrm{BC}$ & $6.9 \mathrm{~B}$ & 27.7AB & $38.8 \mathrm{AB}$ & 33.2BC & 99.2 & 94.4 \\
\hline $45-54$ & $4.8 \mathrm{~A}$ & $5.9 A B$ & $5.3 \mathrm{~A}$ & $51.5 \mathrm{BC}$ & $39.4 A B$ & $45.5 \mathrm{CD}$ & 102.6 & 102.4 \\
\hline $55-74$ & $5.5 \mathrm{~A}$ & $4.6 \mathrm{~A}$ & $5.0 \mathrm{~A}$ & $66.6 \mathrm{C}$ & $83.5 \mathrm{~B}$ & $75.0 \mathrm{D}$ & 106.4 & 105.0 \\
\hline Mean $\pm S D^{\S}$ & $6.5 \pm 2.6$ & $7.0 \pm 2.6$ & & $33.6 \pm 42.1$ & $35.3 \pm 43.5$ & & & \\
\hline
\end{tabular}

* See footnote in Table 1.

$\dagger$ Percentage of cases displaying at least one instance of necrotic atheroma in the specimen.

$\ddagger \quad$ Mean blood pressure $=($ Systolic +2 Diastolic $) / 3$, using age-, race-, and gender-specific data from a survey source (NHANES II[16]).

$\S \quad$ Age by gender-specific means ( \pm standard deviation) is adjusted for race, overall means additionally adjusted for gender.

Note: Main effects of age on stress are significant $(p<0.001)$, but for gender are not $(p=0.27)$. Main effects of age on atheroma are significant $(p<0.001)$, but for gender are not $(p=0.81)$. All interactions of gender with age are insignificant $(p>0.27)$.

When $\mathrm{W}>0$, stress $<5.9$, and atheroma is declared likely to be present. This logistic regression equation with stress measured in units of its standard deviation becomes $\mathrm{W}=3.88-1.38 \times$ Stress with OR $=3.99(95 \% \mathrm{CI}=2.30$ to 6.94$)$. The equation yields $29 \%$ false-negative and $25 \%$ false-positive predictions in the ages 35-74 years using this 5.9 cutoff point. Race, gender, and heart weight were not significant when included into the equation. Age yielded a small positive association with atheroma $(p=0.02)$ if added to the equation, but allowing this age effect to enter changed the coefficient for stress only to $-0.567(-14 \%)$ and the false diagnoses to 28 and $23 \%$, respectively, judged to be negligibly small. Therefore, age was omitted for simplicity. This equation was derived from the 124 men and women of ages 35-74 years having all causes of death, and was tested among the 83 subjects in the age range 18-34 years in Fig. 1. In the figure, odds ratios (ORs) for age groups were calculated from the respective 2 by 2 contingency tables.

\section{SMC Numbers}

Within a longitudinally oriented segment of arterial wall spanning a distance of $100 \mu \mathrm{m}$, and including intima plus media, the number of SMC nuclei varied significantly with age for intima, media, and total wall thickness $(p<0.001$ for each), with ages over 44 years generally having more nuclei than in youth (Table 5). While fewer nuclei were found for women compared to men $(p<0.001$ for intima, media, and overall), the association of number of nuclei with age was similar for men and women $(p>0.12$ for all age-gender interactions). The thicknesses of intima, media, and total wall per SMC nucleus also were associated significantly with age ( $p<0.001$ for each), tending to be higher at older ages (Table 5), but were not associated with gender $(p>0.46$ for each test), and gender did not modify the age effect (all agegender interactions $p$ values $>0.12$ ). 


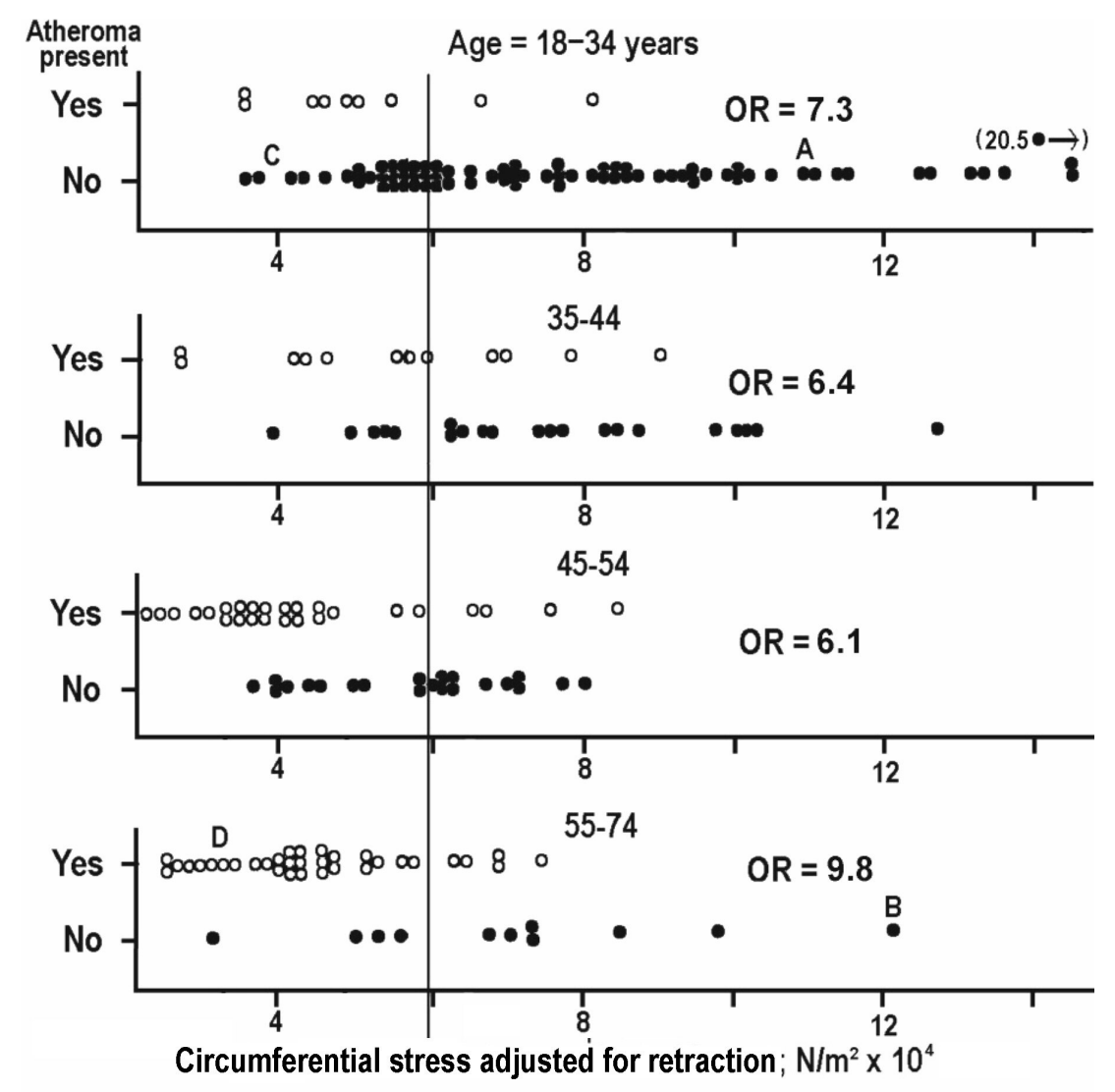

FIGURE 1. Vertical line at abscissa 5.9 plots the equation with $\mathrm{W}=0$, a cutoff point separating Yes from No specimens. ORs are for Yes/No classification. An outlier is noted by 20.5 尺. Letters A-D agree with Fig. 2.

\section{Heart Weight}

Pearson partial correlations between heart weight and other measures were examined, adjusting for age, race, and sex, omitting coronary heart disease. Heart weight was significantly correlated with arterial radius $(\mathrm{r}=0.415, p<0.001)$ and thickness $(\mathrm{r}=0.201, p=0.007)$, but not their ratio, $\mathrm{t} / \mathrm{r}(\mathrm{r}<0.01, p=$ $0.97)$, or circumferential stress $(\mathrm{r}<0.01, p=0.99)$. These findings reflect the fact that radius and thickness vary with heart weight in proportion to each other so that their ratio remains constant at all heart sizes (data not shown), and circumferential stress therefore also remains constant.

\section{Photographic Examples}

Representative examples of young and old subjects with low and high calculated circumferential stresses are compared in Fig. 2. An example of a commonplace youthful subject with high stress (frame A) shows closely spaced SMCs and relatively little matrix that has an open and loose appearance in both intima and media. An uncommon elderly subject who displayed high stress (frame B) shows fewer SMCs, which are more widely spaced in a denser collagenous matrix than that seen in youth. The wall thickness is greater in frame A than B because the youthful artery has recoiled upon excision (excised/in situ length $=\mathrm{f}=0.705$ ) more than the elderly one ( $f=0.791$ ), and thus the two have a comparable circumferential stress after greater downward adjustment of thickness for the effect of retraction. An example of an unusual youthful subject who displayed low levels of circumferential stress (frame $C$ ) shows a thick wall with increased matrix per 
TABLE 5

Age-Specific Means* of Selected Microscopic Features for the Right Coronary Artery in 182 Autopsy Cases with Basal Causes of Death

\begin{tabular}{|c|c|c|c|c|c|c|c|}
\hline \multirow{2}{*}{\multicolumn{2}{|c|}{ Age (Years) }} & \multicolumn{3}{|c|}{ SMC Numbers $^{\dagger}$} & \multicolumn{3}{|c|}{ Thickness per SMC ( $\mu \mathrm{m} / \mathrm{SMC})$} \\
\hline & & Intima & Media & Total Wall & Intima & Media & Total Wall \\
\hline \multicolumn{2}{|c|}{$18-24$} & $10.1 \mathrm{~A}$ & $41.1 \mathrm{~A}$ & $51.2 \mathrm{~A}$ & $8.6 \mathrm{~A}$ & $3.0 \mathrm{~A}$ & $4.1 \mathrm{~A}$ \\
\hline \multicolumn{2}{|c|}{$25-34$} & $11.0 \mathrm{~A}$ & 41.7AB & $52.8 \mathrm{~A}$ & $10.3 \mathrm{~A}$ & $3.4 \mathrm{AB}$ & $4.8 \mathrm{~A}$ \\
\hline \multicolumn{2}{|c|}{$35-44$} & $13.2 \mathrm{AB}$ & $49.1 \mathrm{AB}$ & $62.4 \mathrm{AB}$ & $10.9 \mathrm{AB}$ & $3.3 A B$ & $4.9 \mathrm{~A}$ \\
\hline \multicolumn{2}{|c|}{$45-54$} & $17.2 \mathrm{BC}$ & $55.0 \mathrm{~B}$ & $72.1 \mathrm{~B}$ & $12.6 \mathrm{BC}$ & $3.6 \mathrm{BC}$ & $5.7 \mathrm{~B}$ \\
\hline \multicolumn{2}{|c|}{$55-74$} & $18.0 \mathrm{C}$ & $52.2 \mathrm{AB}$ & $70.0 \mathrm{~B}$ & $14.8 \mathrm{C}$ & $4.0 \mathrm{C}$ & $6.8 \mathrm{~B}$ \\
\hline \multicolumn{2}{|c|}{$\mathrm{Men}^{\ddagger}$, Mean \pm SD } & $15.1 \pm 6.1$ & $52.3 \pm 13.6$ & $67.4 \pm 16.4$ & $11.2 \pm 3.5$ & $3.4 \pm 0.6$ & $5.2 \pm 1.2$ \\
\hline \multicolumn{2}{|c|}{ Women ${ }^{\ddagger}$, Mean \pm SD } & $12.7 \pm 6.3$ & $43.3 \pm 2.1$ & $56.0 \pm 17.0$ & $11.7 \pm 3.6$ & $3.4 \pm 0.7$ & $5.2 \pm 1.3$ \\
\hline 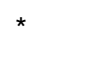 & \multicolumn{7}{|c|}{ See footnote in Table 1.} \\
\hline$\dagger$ & \multicolumn{7}{|c|}{ SMC nuclei numbers in a $100-\mu \mathrm{m}$ wide band through the artery wall. } \\
\hline$\ddagger$ & \multicolumn{7}{|c|}{ Age by gender-specific means is adjusted for race, and overall means additionally adjusted for gender. } \\
\hline Note: & \multicolumn{7}{|c|}{$\begin{array}{l}\text { Main effects of age and gender are significant for SMC numbers in the intima, media, and total wall ( } p \\
<0.001 \text { in all instances). For thickness per SMC, } p<0.001 \text { for age differences of intima, media, anc } \\
\text { total wall, but for gender differences } p=0.47 \text { for intima, } p=0.82 \text { for media, and } p=0.77 \text { for total wall } \\
\text { Interactions of age by gender are all insignificant }(p>0.12) \text {. }\end{array}$} \\
\hline
\end{tabular}

SMC (51\% greater in frame $\mathrm{C}$ than $\mathrm{A}$ ), which spreads the cells apart. Comparing the commonplace elderly example (frame D) with the unusual youthful example (frame C) shows the wall thickening to be more in the intima of the elderly and less in the media. The two examples of low stress arteries exhibited almost no retraction after dissection from the heart $(f=0.923$ and 0.952 for arteries shown in frames $C$ and $\mathrm{D}$, respectively). So the in situ wall thicknesses estimated by adjusting for retraction are little changed from those actually observed in the photographs.

\section{DISCUSSION}

Coronary arteries retract upon removal from the heart. This retraction can produce estimates of the in vivo dimensions that are falsely low for radius and falsely high for wall thickness, yielding deceptive values for circumferential stress. Thus, associations of the stress estimates with other variables, such as age, gender, heart size, etc., will be biased, unless corrections can be applied to adjust for these effects of retraction. This investigation introduces a novel method to correct for coronary artery retraction in postmortem specimens. The method uses longitudinal retraction, which can easily be measured, as a substitute for the desired quantity of radial retraction, which is not easily attainable. The method simplistically assumes that postmortem radial retraction can be treated as proportional to longitudinal retraction. This assumption is not rejected after the following review of relevant literature, and appears to be a reasonable approximation. In our exploratory analyses, we found a number of interesting associations that provide working hypotheses for further consideration.

Some readily available published tabulations of in vivo angiogram determinations provide data for estimating the radius in plaque-free proximal right coronary arteries (RCA) of middle-aged and elderly men; these are $1.83 \mathrm{~mm}[17], 1.70 \mathrm{~mm}[18], 1.60 / 1.65 / 1.65 \mathrm{~mm}[19], 1.81 \mathrm{~mm}[20], 1.54 / 1.29 \mathrm{~mm}[21], 1.80$ $\mathrm{mm}[22]$, and $1.65 \mathrm{~mm}[23]$. The one report[24] that classifies the arteries in terms of dominant circulatory patterns reported RCA radii of $1.50 \mathrm{~mm}$ for a balanced pattern (the most common), $1.90 \mathrm{~mm}$ for small right-dominant pattern, $1.95 \mathrm{~mm}$ for right-dominant pattern, and $1.40 \mathrm{~mm}$ for left-dominant pattern (the 

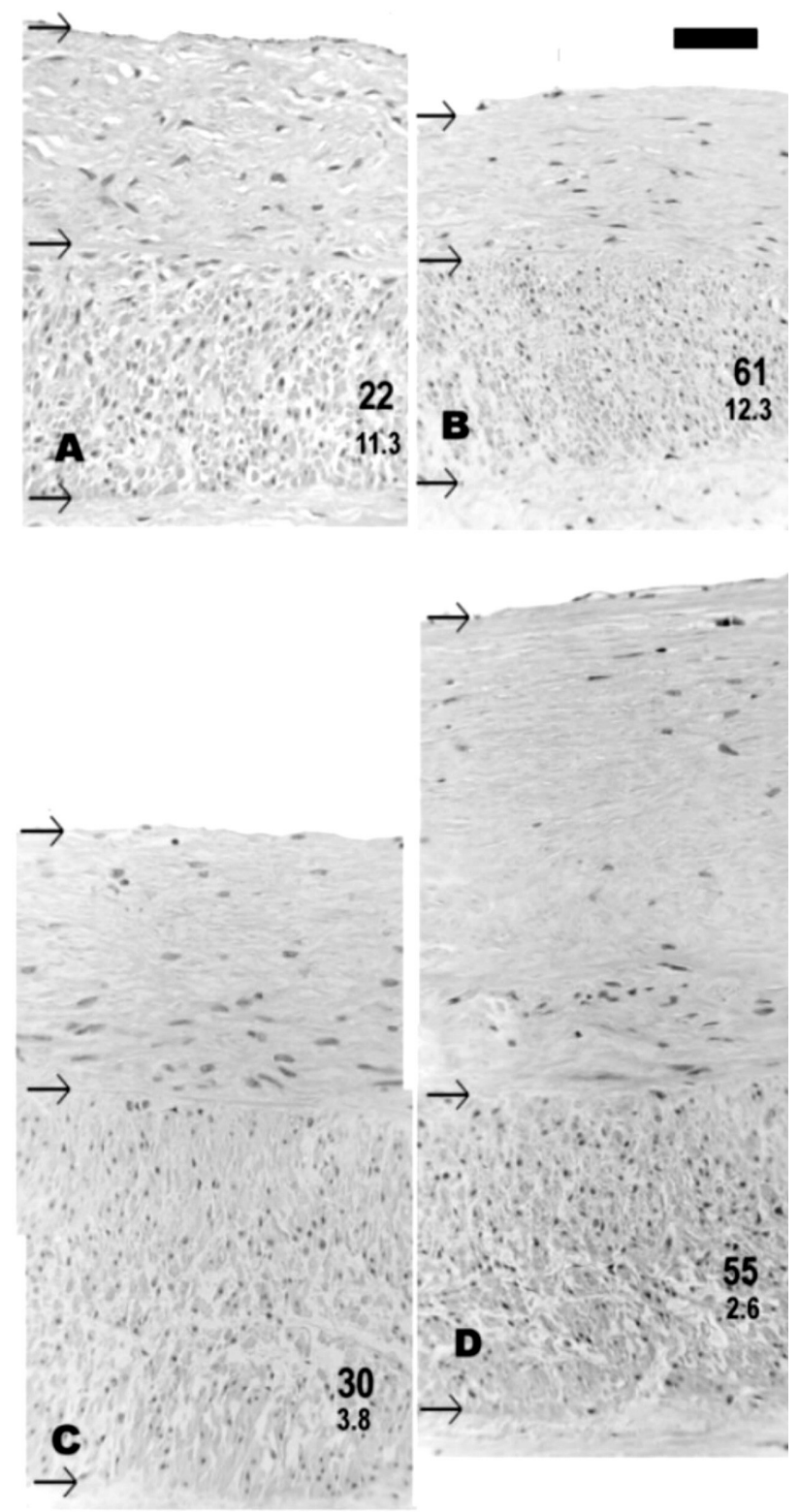

FIGURE 2. Longitudinal coronary planes compare young (A and C) with old (B and D) subjects having high (A and B) and low (C and D) circumferential stresses. Numerals give age (years) over circumferential stress $\left(\mathrm{N} / \mathrm{m}^{2} \times 10^{4}\right)$. Arrows mark luminal surface, intima-media boundary, and media-adventitia boundary. Letters A-D agree with Fig. 1. Bar $=50 \mu \mathrm{m} ; \mathrm{H} \& \mathrm{E}$.

least common). The average of all of the cogent estimates (eliminating left-dominant) is $1.66 \mathrm{~mm}$, which compares with 1.63 and $1.75 \mathrm{~mm}$ for proximal segment in men of ages 45-74 years in Table 2. Although a number of limitations in our study call for caution, these Table 2 findings appear to be in good agreement with the in vivo radiological data. Studies making comparable measurements of inflation-fixed postmortem specimens found radii of $1.96 \mathrm{~mm}[19]$ and $1.87 \mathrm{~mm}[25]$, a 15 and $11 \%$, respectively, discrepancy from the in vivo average. In assessing this discrepancy, Schulte-Altedorneburg et al.[26] measured dimensions of common carotid arteries by ultrasound imaging in patients with late-stage diseases and then repeated the measurements on the carotid arteries retrieved at autopsy. The radii in 
distention-fixed postmortem specimens averaged $9.5 \%$ greater than those in vivo and the excess was attributed to overdistention of the inflation-fixed flaccid postmortem specimens. Bank et al.[27] used ultrasound imaging to measure the luminal cross-sectional area of brachial artery before and after administering sublingual nitroglycerine, and found a $17 \%$ increase of radius in the paralyzed arteries, which seems consistent with the values of 15 and $9.5 \%$ just reviewed.

Bank et al.[27] further determined the arterial luminal area at zero pressures induced by inflation of a cuff on the upper arm. Their estimates of diminished radius from normal baseline were 71 and $84 \%$ obtained by two different imaging techniques, which compares with 75.2 to $86.9 \%$ for dissected retraction in the younger subjects of Table 1. Hence, the circumferential retraction observed by Bank et al. in vivo is similar to the longitudinal retraction in our postmortem specimens, in keeping with our original assumption.

Williams et al.[28] used sensor-tipped catheters in the left branches of the coronary artery in 20 subjects of average age 56.6 years, with plaques only in the right branch to determine wall stress at systolic pressures averaging $139.0 \mathrm{mmHg}$. Their tabulated data allow calculation of the $95 \%$ confidence interval (CI) of 8.97 to 10.53 (mean 9.75$) \times 10^{5}$ dynes $/ \mathrm{cm}^{2}$. For comparison with this, the age-, gender-, and race-adjusted values in the age range 40-69 years in the present study were used to calculate circumferential stress using the value of $139 \mathrm{mmHg}$ for MAP in the formula. This approach neglects the wall thinning that accompanies the higher pressure and is expected to yield a low estimate for circumferential stress. The stress estimates obtained in this way were 6.58 to 7.46 (mean 7.03 ) $\times 10^{5}$ dynes $/ \mathrm{cm}^{2}$. The small discrepancy in these comparisons does not seem to indicate any clear reason to reject our method for estimating postmortem circumferential retraction given the numerous variations in methodology between the two studies.

In the U.S. population, blood pressure rises with age and this contributes to the circumferential stress imposed upon aging arteries. To the extent that the NHANES II survey data of MAP fail to precisely parallel the specific, but unknown, pressures in the subjects of this study, some error will occur in the estimated stress values. However, the nearly twofold rise in thickness-to-radius ratio over the range of ages in Table 3 would require an accompanying increase of MAP to $210 \mathrm{mmHg}$ (e.g., 270/180 $\mathrm{mmHg}$ ) for ages 55-74 years to sustain constant circumferential stress. Clearly, whatever errors may have been introduced by the substitution of survey data for the missing MAP values cannot account for the magnitude of departure from Laplace expectations observed here.

Among women of ages 18-34 years in this study (data not shown), the calculated circumferential stress in the right coronary artery ranged from 14.68 to $5.57 \times 10^{4} \mathrm{~N} / \mathrm{m}^{2}$, a 2.6-fold range (subsample of Fig. 1). This range seems not too unreasonable for a biological variable that is held in physiological homeostasis, and these women might be viewed as representing what is "normal" (cf. Fig. 2A). For men of this age group, however, circumferential stress ranges from 14.53 to $3.55 \times 10^{4} \mathrm{~N} / \mathrm{m}^{2}$ (excluding one outlier), a 4.1-fold range, which seems somewhat harder to reconcile with the concept of homeostatic regulation. This observation raises the possibility that some of these young men may already be acquiring pathological changes of aging[29].

Carallo et al.[30] summarize a widely held view that, "In humans, aging is accompanied by a subversion of arterial wall, which involves splitting and fractures of elastic fibers and increased collagen fibers and intercellular matrix. The vessel becomes larger and stiffer, probably because the relative function of elastic laminae is lost ..." Najjar et al.[31] review the substantial body of evidence that calls for this condition to be viewed as a diagnostic rubric. A name for this condition, "senile ectasia", is credited to Aschov (1924) by Mitchell and Schwartz[32] (cf. Fig. 2D, SMCs are pressed widely apart by the profound increase in densely packed collagenous matrix).

The Laplace Law, s = mr/t (cf. "calculating circumferential stress" in methods), when applied to the data reported here on aging coronary arteries, finds $s$ to vary substantially across age groups, thereby violating the constancy to be expected from findings among normal youthful specimens. However, within age groups, stress remains constant between genders, over the range of heart sizes, and along the lengths of arteries. Hence the arterial response to the forces described by the law appears to behave as expected within age ranges, but to depart from expectation between age groups. A way to summarize these findings 
is to introduce a modification to the usual formula: $\mathrm{s}=\mathrm{kmr} / \mathrm{t}$. If $\mathrm{k}=1$ is chosen for ages 18-24 years, then $\mathrm{k}$ diminishes progressively to $\mathrm{k}=0.58$ at ages $55-74$ years in these data $(5.0 \div 8.6=58 \%$ from Table 4$)$. It is not circumferential stress, $\mathrm{s}$, that remains constant with age, but $\mathrm{s} / \mathrm{k}$, the modified stress term. This study was not designed to investigate possible cell-matrix interactions that might contribute to anatomic changes and reduced circumferential stress. These interactions are objects of intense inquiry and many details are known[2,15,33,34,35,36,37]. One may speculate that $\mathrm{k}$ may herald some changes of cellmatrix interactions, perhaps because of replacement of elastica by collagen for sustaining tension in the aging artery. Anisotropy between arterial layers will be of considerable importance in these considerations[17]. The present study offers no data to comment upon possible molecular mechanisms of this disturbance, but this newly described clue might open novel directions for pursuing these matters.

Increasing age and low circumferential stress were found to be associated with a number of histologic characteristics. An increased prevalence of necrotic atheromas and greater wall thickness per SMC nucleus are two of the interesting findings. Because our study is cross-sectional and had limited risk factors available for study, we cannot determine the sequence of anatomic change or whether some unstudied factor that increases with age caused both the anatomic changes and the low circumferential stress.

Of the many limitations in this exploratory study, three in particular call for some selected comment: (1) stress is distributed heterogeneously across the arterial wall, (2) stress values range widely in the youngest ages, and (3) circumferential retraction is heterogeneous across the arterial wall.

1. With the intimal and medial walls displaying variations between them, and from place to place within them, it seems clear that circumferential stress does not fall equally on all structural elements. It seems plausible to suggest that the subset of elements that sustain the distending forces may be experiencing tensions like those in youth and that much of the wall is to some degree flaccid. However, such heterogeneity fails to explain the existence of those redundant flaccid elements, which are not attempting to adjust their architecture appropriately to the sensed tensions. Indeed, relative to the youthful state, the aged arterial wall is experiencing a degree of laxity, either in whole or in part, and the same dilemma calls for resolution in either case.

2. The youngest women display a 2.6-fold range of measured values for stress. This could be construed as excessive for a variable held in homeostasis. In the men, there is clear evidence that the ectasia of aging is already setting in to some subjects by ages 20-24 years and begins in the media to extend later to intima[29], as illustrated by the example in Fig. 1C. These unusual subjects could account for decreases into the lower range of stress if they also occur in women, a matter that is unclear. The few instances of excessively high stress could be exceptional because their actual blood pressure was lower than the average value applied to them here, or because of exceptional extremes in unrecognized methodological failures. These influences would be further exaggerated if pulse pressure or pulse rate, highly variable quantities, could also impact wall thickness, effects that would cancel out in the group averages. Yet it is hard to presume a range of less than twofold and this seems unreasonably large. Whereas the Laplace expectations can be useful in comparisons of group averages, they are often uncertain when applied to individuals. This discrepancy can be resolved only by further studies.

3. When the dissected artery is opened longitudinally, it sometimes happens that the media shows greater circumferential retraction than the intima. This is observed when the artery inverts to form an inside-out cylinder, sometimes almost to completion. The phenomenon is generally absent before age 30-35 years and again after age 45-50 years. In most specimens, the phenomenon does not occur and therefore poses no problem. When it does occur, the artery is pinned in a way that flattens the intima, leaving the media not fully flat; in these few specimens, the measured circumference is that of the intima (inner circumference) and not the media. This does not necessary translate into greater stress in the in vivo distension of media, because even when distended, the flexible media could remain relative lax compared to the intima. Referring to the 
discussion of topic 1 above, these arteries are presumably among those where a degree of laxity affects part but not all of the arterial thickness.

The architectural changes evolving in aging coronary arteries at sites distant from atherosclerosis are well known in at least broad outline. These changes, however, are widely referred to as "adaptive thickening" and are thought to constitute a form of "normal" intima, often attributed to physiological adaptations in keeping with the Laplace relationships, and having no importance for the evolution of atherosclerotic plaques[12]. In contrast to this conventional wisdom, the present report builds upon a growing body of information that suggests that these architectural changes may have a central place in the evolution of plaques[1,2,3,4,5,6,7,8,31,38,39,40].

\section{ACKNOWLEDGMENTS}

This work was conducted without grant funding. Citations are all to published sources with no outside consultation.

\section{REFERENCES}

1. O’Rourke, M. (1995) Mechanical principles in arterial disease. Hypertension 26, 2-9.

2. Safar, M.E. (2005) Systolic hypertension in the elderly: arterial wall mechanical properties and the reninangiotensin-aldosterone system. J. Hypertens. 23, 673-681.

3. Wolinsky, H. and Glagov, S. (1969) Comparisons of abdominal and thoracic aortic medial structure in mammals. Deviation of man from the usual pattern. Circ. Res. 25, 677-686.

4. Tracy, R.E. (1998) Medial thickness of coronary arteries as a correlate of atherosclerosis. Atherosclerosis 139, 1119.

5. Tracy, R.E. (2003) The course of arterial intimal fibroplasia in aging arteries. In The Role of Aging in Atherosclerosis. Tracy, R.E., Ed. Kluwer Academic, Boston. pp 149-155.

6. Boutouyrie, P., Bussy, C., Lacolley, P., Girerd, X., Laloux, B., and Laurent, S. (1999) Association between local pulse pressure, mean blood pressure, and large-artery remodeling. Circulation 100, 1387-1393.

7. Roman, M.J., Saba, P.S., Pini, R., Spitzer, M., Pickering T.G., Rosen, S., Alderman, M.H., and Devereux, R.B. (1992) Parallel cardiac and vascular adaptation in hypertension. Circulation 86, 1909-1918.

8. Liang, Y.-L., Shiel, L.M., Teede, H., Kotsopoulos, D., McNeil, J., Cameron, J.D., and McGrath, B.P. (2001) Effects of blood pressure, smoking, and their interaction on carotid artery structure and function. Hypertension 37, 6-11.

9. McFarlane, M.J., Feinstein, A.R., Wells, C.K., and Chan, C.K. (1987) The 'epidemiologic necropsy'. JAMA 258, 331-338.

10. Bahr, G.F., Bloom, G., and Friberg, U. (1967) Volume changes of tissues in physiological fluids during fixation in osmium tetroxide or formaldehyde and during subsequent treatment. Exp. Cell Res. 12, 342-355.

11. Siegel, R.J., Swan, K., Edwalds, G., and Fishbein, M.C. (1985) Limitations of postmortem assessment of human coronary artery size and luminal narrowing. J. Am. Coll. Cardiol. 5, 342-346.

12. Committee on Vascular Lesions of the Council on Arteriosclerosis, American Heart Association (1994) A definition of initial, fatty streak, and intermediate lesions of atherosclerosis. Arterioscler. Thromb. 14, 840-856.

13. Emeson, E.E. and Robertson A.L., Jr. (1988) T lymphocytes in aortic and coronary intimas. Am. J. Pathol. 130, 369-376.

14. Eigenbrodt, M.L., Bursac, Z., Eigenbrodt, E.P., Couper, D.J., and Tracy, R.E. (2004) Mathematical estimation of the potential effect of vascular remodelling/dilatation on B-mode ultrasound intima-medial thickness. QJM 97, 729-737.

15. Jackson, Z.S., Gotlieb, A.I., and Langille, B.L. (2002) Wall tissue remodeling regulates longitudinal tension in arteries. Circ. Res. 90, 918-925.

16. U.S. Vital and Health Statistics (1986) Blood Pressure Levels in Persons 18-74 Years of Age in 1976-80, and Trends in Blood Pressure from 1960 to 1980 in the United States. National Health Survey Series 11. No. 234. DHHS Publication (PHS) 86-1684. pp. 48-53.

17. Rutishauser, W., Noseda, G., Bussmann, W.D., and Preter, B. (1970) Blood flow measurements through single coronary arteries by Roentgen densitometry. AJR Am. J. Roentgenol. 109, 2-20.

18. MacAlpin, R.N., Abbasi, A.S., Grollman, J.H., and Eber, L. (1973) Human coronary artery size during life. Radiology 108, 567-576. 
19. Hort, W., Lichti, H., Kalbfleisch, H., Köhler, F., Frenzel, H., and Milzner-Schwartz, U. (1982) The size of human coronary arteries depending on the physiological and pathological growth of the heart, the age, the size of the supplying areas and the degree of coronary stenosis. Virchows Arch. 97, 37-59.

20. Abrams, H.L. (1983) Abrams Angiology. Vascular and Interventional Radiology. $3^{\text {rd }}$ ed. Little, Brown Boston. p. 560.

21. Leung, W.H., Stadius, M.L., and Alderman, E.L. (1991) Determinants of normal coronary artery dimensions in humans. Circulation 84, 2294-2306.

22. Mosseri, M., Zolti, E., Rozenman, Y., Lotan, C., Ershov, T., Izak, T., Admon, D., and Gotsman, M.S. (1997) The diameter of the epicardial coronary arteries in patients with dilated cardiomyopathy. Int. J. Cardiol. 62, 133-141.

23. Makaryus, A.N., Dhama, B., Raince, J., Raince, A., Garyali, S., Labana, S.S., Kaplan, B.M., Park, C., and Juahar, R. (2005) Coronary artery diameter as a risk factor for acute coronary syndromes in Asian-Indians. Am. J. Cardiol. 96, 778-780.

24. Dodge, J.T., Jr., Brown, B.G., Bolson, E.L., and Dodge, H.T. (1992) Lumen diameter of normal human coronary arteries. Circulation 86, 232-246.

25. Rose, G., Pineas, R.J., and Mitchell, J.R.A. (1967) Myocardial infarction and the intrinsic calibre of coronary arteries. Br. Heart J. 29, 548-552.

26. Schulte-Altedorneburg, G., Droste, D.W., Felszeghy, S., Kellermann, M., Popa, V., Hegedüs, K., Hegedüs, C., Schmid, M., Módis, L., Ringelstein, E.B., and Csiba, L. (2001) Accuracy of carotid B-mode ultrasound compared with pathological analysis. Intima-media thickening, lumen diameter, and cross-sectional area. Stroke 32, 15201524.

27. Bank, A.J., Kaiser, D.R., Rajala, S., and Cheng, A. (1999) In vivo human brachial artery elastic mechanics. Effects of smooth muscle relaxation. Circulation 100, 41-47.

28. Williams, M.J.A., Low, C.J.S., Wilkins, G.T., and Stewart, R.A.H. (2000) Randomised comparison of the effects of nicardipine and esmolol on coronary artery wall stress: implications for the risk of plaque rupture. Heart 84, 377-382.

29. Tracy, R.E. (2003) Age of onset of the sex difference in coronary fibroplasia. In The Role of Aging in Atherosclerosis. Tracy RE, Ed. Kluwer Academic, Boston. pp. 233-236.

30. Carallo, C., Irace, C., Pujia, A., DeFranceschi, M.S., Crescenzo, A., Motti, C., Cortese, C., Mattioli, P.L., and Gnasso, A. (1999) Evaluation of common carotid hemodynamic forces. Relations with wall thickening. Hypertension 34, 17-221.

31. Najjar, S.S., Scuteri, A., and Lakatta, E.G. (2005) Arterial aging: is it an immutable cardiovascular risk factor? Hypertension 46, 454-462.

32. Mitchell, J.R.A. and Schwartz, C.J. (1965) Arterial Disease. Blackwell Scientific, Oxford. p. 88.

33. Lehoux, S. and Tedgui, A. (1998) Signal transduction of mechanical stresses in the vascular wall. Hypertension 32, 338-345.

34. Lehoux, S., Castier, Y., and Tedgui, A. (2006) Molecular mechanisms of the vascular responses to haemodynamic forces. J. Intern. Med. 259, 381-392.

35. Tracy, R.E. (2007) Low SMC-densities characterize sites with isolated interstitial lipid in coronary artery intima. Arch. Pathol. Lab. Med. 131, 755-760.

36. Gleason, R.L., Jr. and Humphrey, J.D. (2005) A 2D constrained mixture model for arterial adaptations to large changes in flow, pressure and axial stretch. Math. Med. Biol. 22, 347-369.

37. Holzapfel, G.A. (2006) Determination of material models for arterial walls from uniaxial extension tests and histological structure. J. Theor. Biol. 238, 290-302.

38. Rosvall, M., Janzon, L., Berglund, G., Engstrom, G., and Hedblad, B. (2005) Incident coronary events and case fatality in relation to common carotid intima-media thickness. J. Intern. Med. 257, 430-437.

39. Persson, J., Formgren, J., Israelsson, B., and Berglund, G. (1994) Ultrasound-determined intima-media thickness and atherosclerosis. Direct and indirect validation. Arterioscler. Thromb. 14, 261-264.

40. Wang, M., Zhang, J., Jiang, L.-Q., Spinetti, G., Pintus, G., Monticone, R., Kolodgie, F.D., Virmani, R., and Lakatta, E.G. (2007) Proinflammatory profile within the grossly normal aged human aortic wall. Hypertension 50, 1-9.

\section{This article should be cited as follows:}

Tracy, R.E. and Eigenbrodt, M.L. (2009) Coronary artery circumferential stress: departure from Laplace expectations with aging. TheScientificWorldJOURNAL 9, 946-960. DOI 10.1100/tsw.2009.109. 


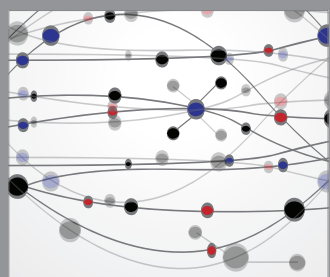

The Scientific World Journal
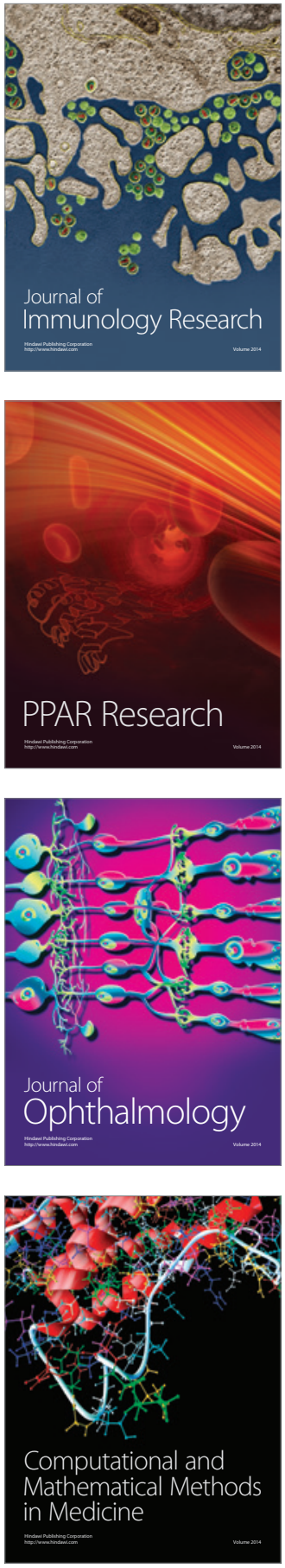

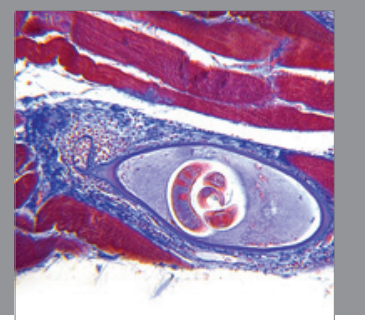

Gastroenterology

Research and Practice
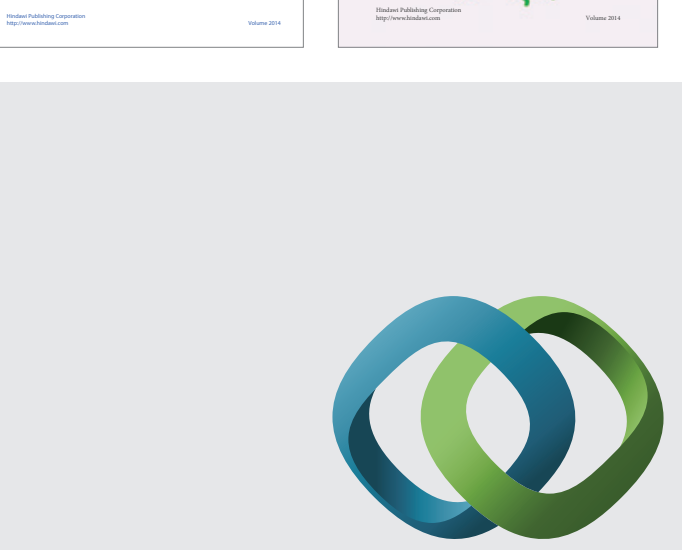

\section{Hindawi}

Submit your manuscripts at

http://www.hindawi.com
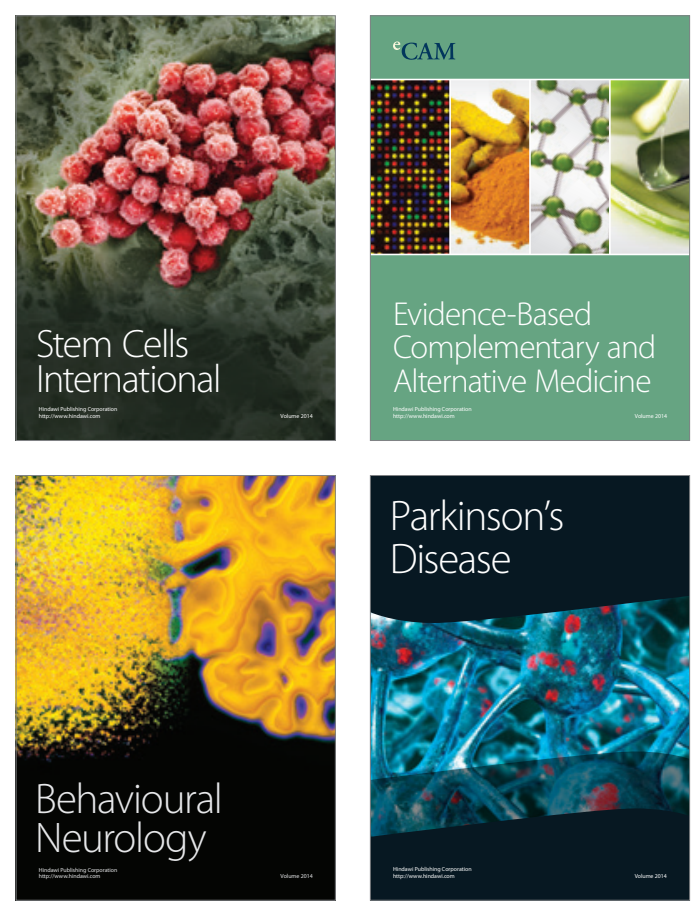

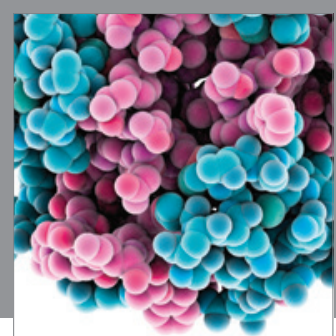

Journal of
Diabetes Research

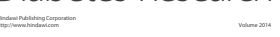

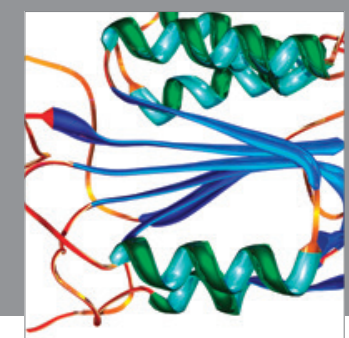

Disease Markers
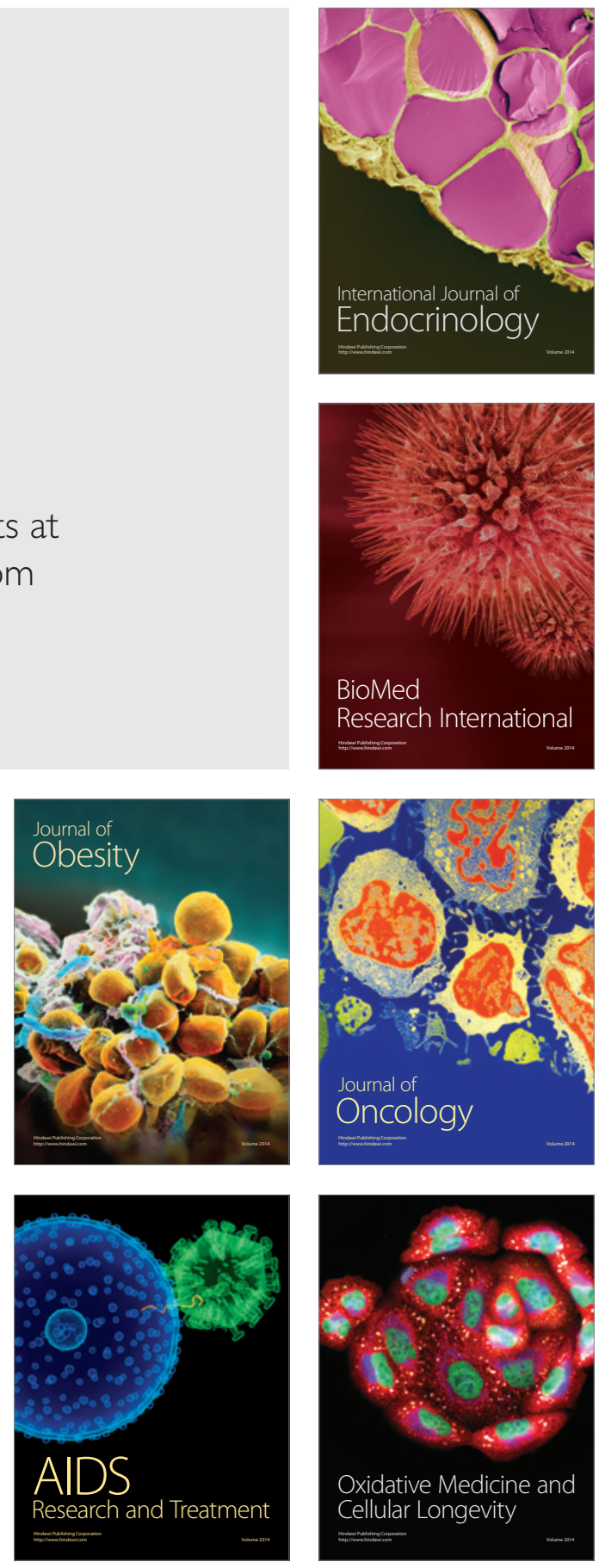